\title{
The MacOdrum Library Of Carleton University
}

\section{By HILDA GIFFORD}

The Murdoch Maxwell MacOdrum liBRARY of Carleton University, Ottawa, was occupied in May 1959. It was the second building completed on a new campus located between the Rideau Canal and the Rideau River and surrounded by Federal District Commission parkways.

Carleton College was opened to night students in 1942 and to day students in 1945. The whole college was housed in one large building until May 1951 when the library moved into new quarters adjacent to the main building. When it became evident that Carleton was not only firmly established but also likely to grow rapidly, it was decided to move to a much larger campus.

Planning of a new library began late in 1955. The librarian and the chairman of the library committee had both worked on the planning of the first library. Both felt very strongly that a building consultant should contribute to the planning of the second library. The college was fortunate enough to obtain the services of Keyes D. Metcalf, who contributed much to the philosophy of the building, as well as to the physical arrangement. Planning went on through 1956, and construction was begun in 1957.

At the time of planning Carleton was envisaged as being until about 1970 a liberal arts undergraduate college, with an enrollment increasing to a thousand day students and an annual library accession rate of about forty-four hundred volumes. In 1961/62 Carleton was a university with 1550 day students and 1350 night students. The library had an acces-
Miss Gifford became Librarian of Carleton College in 1948. She had been a catalog. er at Dartmouth and Dalhousie universities prior to that appointment.

sion rate of about ten thousand volumes and a recorded circulation of over eightyeight thousand. It was fortunate indeed that flexibility had been a prime consideration in planning the library building and that space for expansion had been provided.

The building as completed in 1959 was about 110 feet wide, 200 feet long, and two stories high. The university administration occupied about one third of the main level, which is the second level and slightly above ground. About one third of the lower level was left unfinished. In 1960 part of it was equipped with park benches and tables and was used by "lunch-baggers." In 1961 part was taken over for library expansion and the other part was used as a short-order canteen. In September 1962 the canteen became additional library reading area, and the former kitchen housed an I.B.M. machine.

Construction of three additional floors was begun in June 1962 for completion in September 1963. Only the interior of the third level will be finished at that time, and the fourth and the fifth levels will be finished as required. Total capacity of the building is estimated at over sixteen hundred seats and four-hundred thousand volumes. Located in the capital city of Ontario, which has about a hundred research libraries, Carleton already lends more than it borrows, so it 
is assumed that interlibrary cooperation will make it possible to place some limits on the types of research materials collected. Nevertheless, it is already evident that space on the campus must be reserved for a science library, whose building might also provide storage space for the overflow from the present building.

A number of basic decisions contributed to shape the present Carleton University library. The first was that the building must be simple, flexible, modular, with as few fixed interior features as possible, and easily expansible. Carleton has always had open stacks and expects to continue to do so. Simplicity of arrangement, without special collections or locations, is therefore highly desirable. Carleton is a private institution with no endowments, almost entirely dependent on fees, on federal and provincial government grants, and on private donations. Economy is therefore also highly desirable. Apart from administrative areas, the only fixed units are two stair wells incorporating washrooms and janitors' closets, an elevator, and a row of studies along the north end of the building.

The second basic decision was that the university administration would share the building for at least ten years. Its staff needed an easily accessible location with a separate entrance.

The third decision was that the library administration's quarters should be a unit stretching along the north end of the building from the circulation desk at the exit, back through the cataloging department to the receiving room. With two administrative groups sharing the main level a large floor area was necessary to provide space for circulation, reference, and stack areas between them. Hence the decision to occupy the total site at once, and to expand upwards when necessary. Double occupancy has not presented very serious problems. There is a certain amount of resentment about the locked door between the library and administration as few people appreciate the necessity for controlling all library exits. The main problem arises from the fact that the university administration's area was not planned with a receiving door. Until recently, all mail and most parcels for the whole university were brought to the library's receiving door and up the conveyor into the periodicals and order department. With the growth of the university it became necessary to make another arrangement.

Expansion upward was probably the best solution in our particular situation. In February 1962 it was decided to expand the library on condition that construction should start in May. This was only possible because working drawings and tenders could be prepared very quickly, on the basis of existing plans.

Expansion upward presents many problems which we were not aware of when we decided in its favor. The original plan of expanding floor by floor proved impracticable. The size of the mechanical equipment increases with the size of the building. At each move some mechanical equipment must be replaced either because it has become inadequate or because it has been damaged in transit. This promised to be so expensive that it seemed preferable to add three levels at once and put the mechanical equipment for the total building into its final location. Expanding upwards may not be more expensive than expanding horizontally, but it does not appear to be cheaper, even though no foundation is involved.

Construction of upper floors is attended by the dangers of leaks, fires, and theft. We have been unfortunate in our contractor. In spite of many promises and supervision by a resident inspector, adequate care has not been taken of library property. Due to carelessness we have had serious leaks down columns, elevator shaft, and stair wells. There has not yet been damage to books, but the carpet has been soaked so extensively that it may well all have to be replaced. Improvements of the ventilation system 
and its expansion to serve the total building have necessitated extensive work on the ceiling of both the existing levels. The welders have not caused a fire, but plumbers, electricians, plasterers, and painters have all left their marks on furnishings and carpet. The books must all be vacuumed, but so far as we know only a few have been damaged.

A decision not to provide staff supervision of reading rooms strongly influenced the arrangement of furniture and shelves within the building. The circulation desk controls exit and entrance. Otherwise, supervision is exercised only by the stack supervisors and other staff members looking for books. In the former library the main reading room faced the circulation desk. The staff was usually too busy to observe the reading room, and the traffic at the desk was a disturbing influence in the reading room. The abandoning of formal supervision made it possible to provide reading space close to all books. Traffic is concentrated in a central corridor running from end to end of each level. The two stair wells and the elevator open at right angles on to this corridor. The book stacks are arranged at right angles on either side of it, with reading areas around the perimeter of the building. Nowhere are books more than thirty feet from reading tables. Experience has shown that the narrow reading areas close to the books are quieter than open areas. A problem of discipline existed in an open area at the foot of the main stairs. The problem was solved when some of the reading room tables were replaced by carrels and additional ranges of books. With student population increasing by 25 to 35 per cent each year supervision of reading areas may become necessary later. It would probably be the responsibility of the stack supervisors.

The central corridor, the stacks, and the reading areas are nowhere separated by partitions. This open arrangement made sound control a very important consideration and lead to the decision to use carpet as the floor covering throughout the building, except in the main entrance lobby. The university's bursar estimated that if the carpet wore well for ten years, the saving in maintenance would pay for the extra cost. The carpet has suffered seriously in the recent building phase, but otherwise it has proved generally satisfactory and is to be used in the extension. The students have lockers in the tunnels joining campus buildings and therefore do not track in much snow, sand, salt, or mud.

The circulation desk is at the left of the exit and makes it necessary for patrons to enter and go out by doors at their left instead of at their right. So strongly ingrained is the instinct for traffic to flow to the right that newcomers almost invariably fumble like blind men at the exit doors, which have no handles to open them. Incoming and outgoing traffic are separated by a counter with book return slots through which books are dropped into depressible book trucks. This counter can be used as an additional checkout point at rush hours.

The studies across the north end of the lower level were intended for small discussion groups as well as for advanced students seeking privacy. The partitions are made of expensive prefabricated panels and glass. The panels were especially designed to reduce sound transmission. Unfortunately they could not be made to fit tightly to the floor, dropped ceiling, or columns and so were not soundproof. On the third level, the partitions will be solid from floor to slab. A smoking lounge will occupy a corner of the building beyond them.

Carleton is unusual in having no reserve book room. By tradition assigned readings and assigned texts have not been heavily used. Circulation of reserve books is recorded in detail and reported to faculty members regularly. The small collection of closed-shelf reserves can be kept at the circulation desk. One-week reserve books and "class duplicates" for use in the reading room only are on the 
open shelves. All are covered with reserve jackets which seem to be a psychological deterrent to stealing. Losses have been irritating but have not yet reached serious proportions. The students' council last year included library regulations in the "honour system," their form of student government. If a reserve book room does become a necessity it will be easy to partition off some convenient area for it.

Good lighting was one of the most important considerations in planning the interior. We wished to obtain fifty footcandles of light at the surface of reading room tables and to avoid all visible sources of glare. We selected a luminous plastic ceiling similar to the Wakefield type. It consists of long strips of plastic three feet wide suspended on metal T-bars. We find it attractive but have decided against having it on the third level. The plastic chips easily, and maintenance is costly. The number of tubes necessary to give a ceiling without shadows generated excessive heat and were excessively expensive to operate. The metal T-bars which support the corrugated plastic are a complicating factor where partitions are required.

In selecting furniture we changed from blonde birch and Kalistron to oiled walnut. We chose oiled walnut because we preferred its appearance. Readers appear to share our preference and unconcern for the contrast in brightness ratios between the desk table tops and white pages. There is less temptation to doodle on a dark surface and carving has not been a problem. The carrels around the exterior of the reading rooms are very popular. They have oyster white arborite tops. Some lounge chairs are used, but the students do not seem to favor many of them in the addition.

One major decision made in planning the building has been reversed in planning the extension. We felt that we could not afford air-conditioning, but apparently curtain-wall construction requires it. The elegant exterior of the building consists of prefabricated panels of fiberglass alternating with strips of glass, the two separated by white fins. The fins provide some shade but also reflect heat into the building. Vertical venetian blinds provide protection from direct sunshine, but also absorb heat and radiate it into the building. The insulating core of the panels is phenol-impregnated paper honeycomb with three-quarter inch cells. The U-factor is much higher than it should be. The panels of the extension are guaranteed to have a U-factor of .15 or lower, but air-conditioning will still be necessary. The windows are hinged at the top and open out from the bottom. They do not let in enough breeze to cool the building to outside air temperature.

Three years is a very short period in the life time of a building but expansion of 100 per cent is a fair test of planning, and this the Carleton library has experienced within the three year period.

\section{Not More Than a Handful}

If, as most educators claim, the library is the heart or center of the university, certainly the catalog is the heart and center of the library. ... It performs many services for those who are sufficiently sophisticated to use them. In analogy, some of us would have difficulty in using [a] computer to add two and two, while our more knowledgeable colleagues use it to compute orbits. So it is with the catalog which must be both an abacus and an electronic brain, equally useful to the most naive freshman and the senior scholar. There are not more than a handful . . sufficiently, sophisticated to use the card catalog to its maximum potential.-University of Cincinnati's News Notes From the Library, May 1961. 